\title{
A Mestra da Ciranda: Entrevista com Lia de Itamaracá
}

The master of Ciranda (a typical dance in circle in Brazil): Interview with Lia from Itamaracá

Por: Renata Celina de Morais Otelo ${ }^{1}$

e Marcílio de Souza Vieira ${ }^{2}$ 
A Cirandeira Lia de Itamaracá, em entrevista realizada, em 30 de Agosto de 2014, na Ilha de Itamaracá, Pernambuco, na residência do produtor artístico de Lia de Itamaracá, Beto Hess ${ }^{3}$.

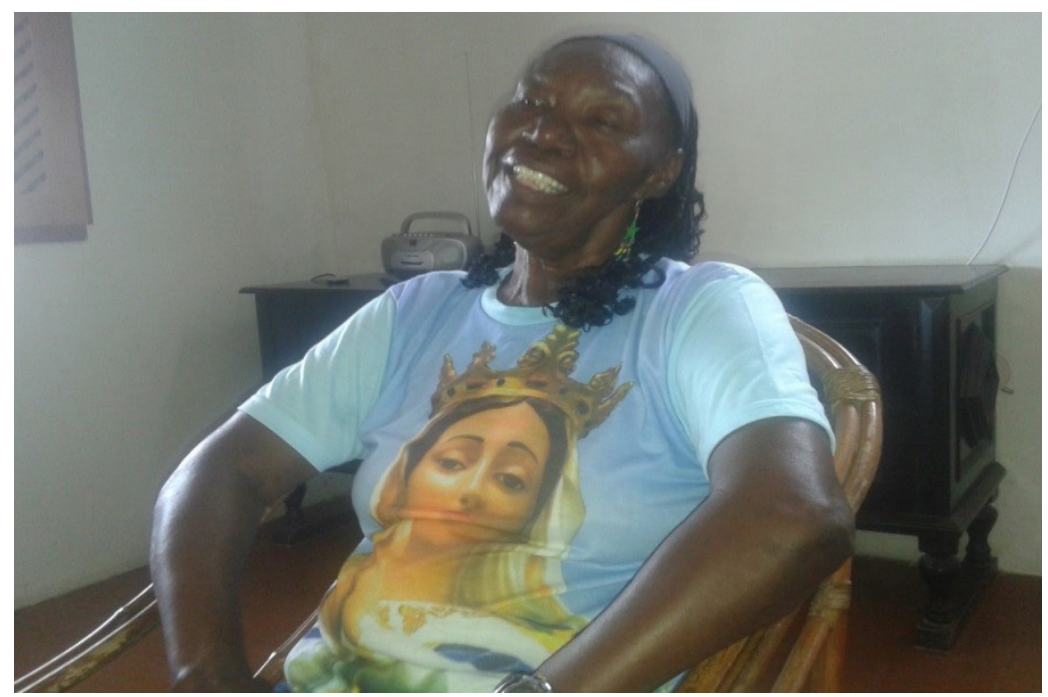

Entrevista com Lia de Itamaracá em 30 de agosto de 2014.

Foto: Arquivo pessoal de Renata Otelo. 


\section{Apresentando Lia de Itamaracá}

A Cirandeira conhecida por Lia de Itamaracá, traz em seu registro o nome de Maria Madalena Correia do Nascimento. Mulher negra, nascida em 12 de Janeiro de 1944, na llha de Itamaracá, Pernambuco.

Foi na ltha que começou a participar de rodas de Ciranda desde os 12 anos de idade. Foi a única de 22 filhos a se dedicar à música. Segundo ela, trata-se de um dom de Deus e uma graça de lemanjá, sua mãe protetora.

Mulher simples, com 1,80m de altura, canta e compõe desde a infância e hoje é reconhecida no Brasil e fora do país, como expressão da cultura do Nordeste Brasileiro.

Iniciou sua trajetória nos anos de 1960 e é a fonte de um refrão famoso, da compositora Teca Calazans: Esta ciranda quem me deu foi Lia/ que mora na ilha de Itamaracá.

Em 1977, Lia gravou seu primeiro disco, intitulado A Rainha da Ciranda, não recebendo, no entanto, nenhum pagamento pelo trabalho. Em 2000, saiu seu CD Eu Sou Lia, lançado pela Ciranda Records e reeditado pela Rob Digital, cujo repertório incluía Coco de raiz e loas de Maracatu, além das Cirandas. Essa configuração é ainda hoje utilizada em suas apresentações artísticas em que a Cirandeira divide seu repertório em blocos musicais com esses ritmos.

Ela é considerada como Patrimônio Vivo do Estado de Pernambuco. Em 2005 recebeu o título de Comendadora da Ordem do Mérito Cultural do Governo Federal. Lia de Itamaracá é uma espécie de "lenda" viva, que permanece morando na Ilha de Itamaracá, seu lugar de inspiração compositiva e foi desta mulher que fomos ao encontro.

No universo da cultura popular, nos propusemos a uma conversa descontraída com intuito de acessar a vida, a memória, a arte e ouvir desta artista as expectativas aguardadas em relação ao poder público de sua terra. 
Beto Hess, produtor de Lia, iniciou um papo simples e espontâneo aos ao nos receber:

"O povo me pergunta: você é marido de Lia? Não. Você é filho de Lia? Aí eu digo: não, não sou filho dela não. Mas Lia é sua mãe de Santo? (risos) Ficam buscando alguma coisa!" Nesse instante Lia complementa dizendo:

"O povo viaja demais... viaja demais... (risos)".

Era manhã de um sábado ensolarado.

\section{E como é que a senhora se apresenta?}

Maria Madalena Correia do Nascimento e Lia como artista.

\section{Nome artístico que a senhora escolheu ou foram nomeando?}

Como você poderia ser chamada? Maria, ìa, Lia... veio a Ciranda pra acabar de casar e ficou Lia da Ciranda.

\section{Antes de cantar Ciranda, já dançava ou já foi tudo junto?}

Eu comecei com 12 anos de idade. Com 19 anos assumi responsabilidade. $\mathrm{Na}$ minha família ninguém canta, ninguém dança, num sabe pra onde vai. Só quem deu pra cantar fui eu. De uma família de 18, 19 filhos, fora os que morreram e agora de tudinho resta eu. Da parte de pai ainda tem 4 mulheres e 2 homens. $O$ resto Deus levou tudo.

\section{O que a senhora sente quando dança, quando canta e quando vê as pessoas acompanhando?}

Eu fico feliz... é uma maravilha! É um trabalho que é um dom que Deus me deu! É meu sonho realizado. Todo meu sonho era cantar e eu gosto de fazer e adoro fazer.

\section{Acha diferente a maneira de dançar Ciranda atualmente?}

Muita gente quer modificar os passos da Ciranda que não é para fazer isso, mas enfim, eu não posso proibir. É de cada um.

\section{Tem diferença cantar Ciranda aqui e ir para outros lugares?}

Aqui é minha praia. É diferente de outras praias, de outros setores... mas eu enfrento, gosto, adoro, sou bem recebida e aonde Lia vai já vai com todo Axé! A Ciranda é todo mundo de mãos dadas, é uma dança de roda, a Ciranda não tem preconceito; na Ciranda dança pobre, dança rico, dança aleijado, todo mundo! É uma maravilha. A 
Ciranda casa e batiza. Às vezes tá tão amuado em casa, pensando: "Meu Deus, que é que tem pra gente vê? Não tem nada"; Tem uma roda de Ciranda! Vamo lá? Aí você já vai com aquele astral, se anima e quer chegar ali. E é um andamento muito bom, muito lento e bonito. Eu adoro. Faço todo mundo feliz. Tenho contato com todo mundo.

\section{Soube que no seu aniversário tem uma grande festa, né?}

É. Aqui eles fazem a Ciranda em homenagem ao aniversário de Lia. É todo dia 12 de Janeiro. Tem a festa do Padroeiro ali de Bom Jesus e nessa festa do Bom Jesus tá consagrada a data do nascimento de Lia. Pra eles vê se me seguram porque senão eu vou embora e é pior pra eles.

\section{E será que a senhora ía saber viver sem a Ilha?}

Viver sem a llha não. Mas sair pra não voltar, também não. Aqui é meu respiro, aqui é minha praia. Mas procurar minha felicidade, meu meio de vida .... eu vou embora!

\section{E o que significa a Ciranda pra senhora, pra sua vida?}

Olhe, a Ciranda é uma dança que contagia todo mundo. É uma dança que alegra o povo. Eles brincam com alegria, com felicidade, muita verdade e isso ama ainda mais Lia. Todo mundo faz a Ciranda girar.

\section{A senhora se sente amada...}

Com certeza. Quando sai, sai mais amado ainda por que dançou, curtiu Lia, tomou sua cervejinha, tomou umas e outras e vai pra casa feliz. Se tem briga em casa a briga não vai existir mais. Aí vai partir pro abraço, pra o amor, pro carinho aí no sábado vai de novo (pra Ciranda) (risos).

\section{E sobre o que aconteceu com o Espaço Cultural?}

O Espaço Cultural, ele caiu no dia 09 de Janeiro (2014). Teve o aniversário de 70 anos de Lia e veio um jornalista do Jornal do Comércio. Jornalista veio pra me entrevistar sobre o aniversário de Lia, como é que era, tocou da morte de Reginaldo Rossi, o que eu tinha sentido com a morte dele...Aí ele disse: Lia quero ir no Espaço Cultural. Eu disse: olhe, o Espaço Cultural não tem condições de receber ninguém. Nem eu mesma vou ali. Ele caiu. Aí ele disse: deixe a chuva cessar um pouquinho (tinha chovido muito) que daqui a pouco a gente vai lá. Eu quero tirar umas fotos da senhora no Espaço Cultural. Tudo bem. A gente vai no Espaço Cultural. E tinha pouco tempo que ele tinha caído.

\section{Caiu com as chuvas?}


Sem manutenção. Beira de praia. De madeira. Eu sem poder, sem ter condições de fazer manutenção dele. O prefeito que saiu prometeu ajudar, deu o caô dele, saiu que nem a Ciranda pagou de dois shows. Saiu e não pagou. Quer dizer, eu e Beto que tirava dinheiro das casas da gente pra pagar os shows de todo sábado... tá aí, o Espaço Cultural. Sem ter ajuda de nada, sem ter manutenção. As vezes o SESC patrocinava. Tinha outro, às vezes ficava dois, três meses (patrocinando) e ali quando acabava o patrocínio, partia de novo pro bolso da gente. Quer dizer que eu e Beto tava numa situação de pagar, tirar do bolso da gente pra fazer ali o Espaço Cultural que é uma responsabilidade muito grande. É responsabilidade com energia, é com o bar pra vender a cervejinha, o refrigerantezinho, o tiragostozinho, tem os funcionários e a gente tem responsabilidade com eles pra pagar, vem a água, o transporte pra buscar esse povo no Recife. Tem músico na Paraíba, tem músico no Recife que você leva tapa na cara pra fazer, a gente vai buscar pra fazer bonitinho. Depois que a gente faz eles viram as costas. Faz de conta que não foi com a gente que ele fez o contrato. Como é que se pode trabalhar num lugar desse? É difícil. Muito difícil. Aí eu peguei e falei pro prefeito:

Olhe, só tem uma solução; o que você prometer você não fez, descumpriu. Eu vou parar com a Ciranda. Eu faço Cultura, eu vou parar com a Ciranda. É uma pena porque na comunidade não tem pra onde ir, tem Ciranda de Lia todo sábado, mas vou parar com essa prenda muito tempo porque vocês não querem me ajudar! Então tá, tá tudo como vocês querem!

Sei que aí fomos simbora.

Fazia pouco tempo que o espaço Cultural tinha caído. Eu disse ao jornalista: tá vendo o resultado, eu falei pra você. Ele disse "Lia, é um presente de aniversário? (ironiza) Vou jogar tudo isso na televisão." Já que tá aqui, joga pra dentro! Eu num falei pra você em casa. É um presente de aniversário (ironiza também).

Quando é uns dois dias depois vem os funcionários mandado do prefeito, do governador dizendo que ía ajudar, se for preciso ajudar papapá e viremexe...tudo bem. Nessa ajuda marcaram umas reunião comigo e Beto na Casa Civil e passou, e ele só cozinhando: a gente tem um arquiteto! E mandou o arquiteto e lá vai e lá vai... Chega pensa que não, o homem morre. O que ía me ajudar, morre: Eduardo Campus. Agora, vamos vê o que é que vai acontecer. Se ele deixou alguma coisa pra o que entrou no lugar dele, tudo bem; senão, eu não sei o que é que vai acontecer com a gente. Vamos fazer alguma coisa, fazer uma campanha pra vê se levanta esse espaço. Não é que Lia teja morrendo de fome não porque graças a Deus eu tô muito bem, mas é a música. É com a Música. Lia hoje tá viva. Lia amanhã tá morta. E se eu não puder alcançar o que eu quero agora, mais tarde 'Inês é morta'.

\section{Vinha muita gente, dona Lia?}

Vinha! Oxe, ave Maria minha filha! Vinha, vinha demais, todo sábado! Fazia a Ciranda todo sábado ali no Espaço Cultural. Dava oficina de percussão, de música, de cerâmica, de guache, de giz de cera, fazia um bocado de coisa. E vinha professora de 
Recife pra fazer, sair bonitinho quando tinha projeto. Quando não tinha parava, como parou até hoje.

Então Lia de Itamaracá, uma personalidade conhecida no Brasil todo e talvez até fora, na sua terra, no seu lugar, não é valorizada.

Na minha terra eu não tenho prosperidade de nada por conta do governo, porque pelo povo sim. Porque eu tô há uma semana aqui e o povo fala de Lia de Itamaracá. Lá em Recife eu passei a semana cantando as Cirandas de Lia com o pessoal. O povo tem uma paixão pelas Cirandas. Mas o Governo, não investe. E quando promete, aconteceu o que aconteceu. Deixou todo mundo chocado ( a morte de Eduardo Campus).

As pessoas também lhe consideram, como a gente tava falando, uma deusa, uma entidade. $O$ que a senhora acha disso?

Eu acho tão bom! (risos) Eu adoro minha fia; már menina, vai ter pena! (risos).

Eu já vi vários artistas falando da senhora, na Bahia tem Mariene de Castro, que é uma grande sambista, canta samba, samba dos terreiros, todo show ela faz Ciranda, ela sempre começa com a Ciranda e ela já falava da grande mulher, da mulher negra, essa mulher forte e guerreira que é Lia. Marisa Monte...

Marisa Monte quando vem fazer show já vem com meu nome na agenda dela. Quando ela parte pro Recife, ela me avisa pra eu participar do show dela e eu vou. Bota as coisas debaixo do braço: bora neguinha! (risos)

\section{Lia você é muito simpática! Muito simples!}

Às vezes eu tô ali na porta, na calçada, aí o povo passa: "né ela não!" e eu só ouvindo (risos). "Né ela não, é a mãe dela". "Você não escuta televisão não? Você não escuta não? A mãe dela é morta". "Então é a irmã!" e vai até longe da estrada e eu só pegando. Mas é assim. Depois que as fichas deles caem: "ah! A senhora que é a dona Lia? Passei pela sua porta". Eu digo: não falou comigo porque não quis (risos). Saiu em dúvida, em dúvida, em dúvida...

\section{A senhora tem seus trabalhos guardados? Cartazes, CD?}

Tem cartaz. A maioria tá com Beto. Tinha CD, mas essas andança minha levando pra Brasília, São Paulo, levou tudo. Depois fizemos um projeto mas os CDs que tinha já se foi. Se tiver dois ou três é com Beto. Eu mermo não tenho mais nenhum. Agora a gente vai tentar gravar um DVD. Vai demorar, mas eu tenho fé em Deus que vai sair. Trabalhar agora pra DVD. Já fui atrás de patrocínio, atrás de produtores pra gravar o DVD. 


\section{Beto apareceu quando a senhora já tinha passado por algumas coisa, né? Deu certo essa parceira?}

Já tem onze anos que trabalho com Beto. Graças a Deus até hoje nós somos parceiros, amigos de trabalho, de tudo. Até hoje somos. Eu não tenho nada contra ele. Se alguém tem procure se ajudar e se falar mal dele na minha frente eu rebato.

\section{Lia, a senhora também é compositora. A senhora saberia dizer quantas Cirandas já compôs?}

Minha amiga, olhe, eu já perdi a prática. Quero ajeitar os parafusos do cérebro pra vê se consigo mais músicas pra esse DVD. A idade vai chegando, o vai querendo se separar (risos). Aí é facebook, é internet, e bota de novo e bora vê como é que vai. Vô pra bera da praia, me sento, escrevo uma letra, a onda vem apaga eu volto a escrever e por aí vai.

Eu já vi uma Ciranda que as pessoas sempre começam cantando "Eu tava na beira da praia ouvindo as pancadas nas ondas do mar"...aí a senhora sempre começa com essa? Essa Ciranda é da senhora?

Ela é minha com Teca Calazans. Essa Ciranda tem uma polêmica muito grande. Porque Teca Calazans teve aqui em 62; essa música ficou envolvendo meu nome. Teca Calazans quando caiu em si já tinha cantado em tudo que é terreiro e teve um que gravou registrou a música e disse que era dele. Ele tem uma Lia, e disse que a música é dele. Mas quem ganha os direitos dessa música não é nem esse cara que gravou e registrou, é outro tão diferente: Ô glória! Pra deixar de ser safado (risos). Não vou atrás de briga, não fiz briga nem quero briga, eu sou da paz, mas ...

\section{E essa Ciranda quem me deu foi Lia, quem fez essa?}

Eu e Teca Calazans. Eu fiz a ponta e ela completou. Ela fez uma entrevista, disse que não lembra de mim, não lembra que teve comigo. Ela ficou com medo, eu acho que ela ficou com medo, deu botar questão em cima dela. Besteira dela. A única pessoa que me apoiou. Ela devia dar as mãos pro céu e agradecer a Deus que a música tá aí no ar até hoje. Foi bobagem dela. Onde eu vou ainda canto. Ainda bem que não mudaram uma letrinha "quem me deu foi Lia" quer mais o quê? Már menina, óia, eu tô aqui bem 'tchan'! (risos).

Muita gente vem aqui: "como é essa Lia meu Deus? Isso é uma lenda". Pensa que vai me encontrar bem gorda, gagá, que não conheço mais nada, e eu tô aqui bem 'tchan'. Eu digo que nem a mulhé: "boto pa torar".

\section{E a fé de Lia? Me fale um pouco da sua fé...}

Não sou mãe de santo. Sou católica apostólica romana. Se tem o Candamblé eu vou vê como é que é. Eu sou filha de lemanjá.. Na terra espiritual eu sou filha de 
lemanjá. Num tem nada de candomblé não. Ela é uma maravilha! Nunca pedi nada a minha mãe pra ela dizer 'vai timbora que num eu gosto de tu não'. Maravilha, uma maravilha! Ela é do mar. Esse marzão todinho. Ela é dona de ponta a ponta.

O povo vem perguntar: Onde é seu terreiro? Meu terreiro é aqui, na porta de casa, no jardim. (risos)

Outro dia o padre me disse assim: "Olhe, né que eu seja contra a Ciranda não, nem as músicas, nem à você não; mas, dia de sábado, dá pra senhora esperar eu celebrar a missa?"

Eu disse: Pois não, Padre. Sua palavra é um pedido. O senhor é uma autoridade.

Ele disse: apois é. Porque muitas vezes tô celebrando a missa e muitas mulheres, beatas da igreja, elas ficam dançando dentro da igreja (risos)

\section{E a senhora pensando que tava atrapalhando.}

O Padre disse: Enquanto eu tô pregando eu tô notando que elas tão fazendo assim (mexendo os ombros em movimentos de dança). Risos.

Ele disse que é muito forte o batuque do Côco, do Maracatu e que os santos só faltam cair, que é muito forte e é em cima da Igreja! Não Padre, por isso não, só vou fazer a Ciranda, só vai usar som depois que celebrar essa missa. Depois que acabar vão tudinho pra Ciranda. É animado o povo!

E em meio a risadas, a feitura do almoço e o observar do entardecer na llha de Itamaracá, que tivemos o privilégio de passar aquele dia com essa Mestra, cheia de carisma e amor por sua terra. Obrigada Lia de Itamaracá! Axé!

Recebido em: 01/05/2015

Aprovado em: 20/07/2016 